\title{
Short communication: Effect of manipulating fatty acid profile on gluconeogenic gene expression in bovine primary hepatocytes
}

\author{
K. A. Weld, S. J. Erb, and H. M. White* \\ Department of Dairy Science, University of Wisconsin, Madison 53706
}

\section{ABSTRACT}

During the peripartum period, dairy cows experience both an increase in circulating fatty acid (FA) profile and a change in circulating FA profile, which have been shown to alter regulation of gluconeogenic genes. The objective was to quantify gene expression of key enzymes involved in gluconeogenesis and FA transport into the mitochondria in primary hepatocytes in response to exposure to an FA mixture mimicking what is circulating in a transition dairy cow with or without enrichment of C16:0, C18:0, and C18:1. Primary hepatocytes were isolated from 4 Holstein bull calves $3 \mathrm{~d}$ of age ( \pm standard deviation $2 \mathrm{~d})$ and cultured. Twentyfour hours after plating, treatments were applied to the cells for 24-h incubation. Treatments consisted of (1) control (1\% BSA), (2) $0.75 \mathrm{mM}$ FA cocktail (3\% C14:0, 27\% C16:0, 23\% C18:0, 31\% C18:1, 8\% C18:2, and $8 \% \mathrm{C} 18: 3$ to mimic the FA profile of dairy cattle at calving), (3) $0.90 \mathrm{~m} M$ FA cocktail, (4) $0.75 \mathrm{~m} M$ FA cocktail + 0.15 mM C16:0, (5) $0.75 \mathrm{~m} M$ FA cocktail + $0.15 \mathrm{~m} M \mathrm{C} 18: 0$, and (6) $0.75 \mathrm{~m} M$ FA cocktail +0.15 $\mathrm{m} M$ C18:1. After harvest in Trizol (Life Technologies, Carlsbad, CA), samples were stored at $-80^{\circ} \mathrm{C}$ until RNA extraction, purification, and reverse transcription. Abundance of mRNA was measured using quantitative real-time PCR. Expression of genes of interest [carnitine palmitoyltransferase $1 \mathrm{~A}$, pyruvate carboxylase, cytosolic phosphoenolpyruvate carboxykinase (PCK1), mitochondrial phosphoenolpyruvate carboxykinase, and glucose-6-phosphatase] was calculated relative to the average abundance of 2 reference genes (ribosomal protein L32 and glyceraldehyde 3-phosphate dehydrogenase), which were the most stable out of 3 tested. Data were analyzed using PROC MIXED (SAS version 9.4; SAS Institute, Cary, NC) with the fixed effect of treatment and calf in the random statement. The addition of FA compared with the 1\% BSA treatment increased

Received December 11, 2018.

Accepted April 22, 2019.

*Corresponding author: heather.white@wisc.edu the expression of carnitine palmitoyltransferase 1A and cytosolic PCK1. Enrichment with individual FA did not further regulate pyruvate carboxylase or PCK1 beyond that achieved by the basal profile. These results suggest that shifts in circulating FA profile within a biological range, without a difference in the total FA concentration, have minimal effects on transcriptional regulation of hepatic gluconeogenic genes in primary bovine hepatocytes.

Key words: liver, pyruvate carboxylase, transition cow

\section{Short Communication}

During the transition to the lactation period, dairy cattle experience shifts in circulating fatty acid (FA) profile and concentration relative to parturition (Rukkwamsuk et al., 2000). Additionally, induction of postpartum fatty liver (Rukkwamsuk et al., 2000) or prepartum dietary fat supplementation (Douglas et al., 2007) result in further differences in pre- and postpartum plasma FA profiles; similarly, hyperketonemia is related to changes in circulating FA profile through the transition period (Weld et al., 2018). Changes in FA profile and concentration have been shown to regulate the expression of genes involved in hepatic gluconeogenesis and FA transport (White et al., 2011a; Bionaz et al., 2012; White et al., 2012). For example, in MadinDarby bovine kidney (MDBK) cells, capable of these functions to a lesser extent, carnitine palmitoyltransferase 1A ( $\boldsymbol{C P T 1 A})$ is responsive to $\mathrm{C} 16: 0, \mathrm{C} 18: 2, \mathrm{C} 18: 3$, and CLA in a concentration- and FA-specific manner (Bionaz et al., 2008). Understanding the regulation of these major pathways in the liver during the transition period is of vital importance due to both the increase in circulating FA from mobilized adipose tissue, which the liver must process, and the increased glucose requirement to support lactation.

The capacity of the liver for FA oxidation via the tricarboxylic acid (TCA) cycle versus supply of precursors to gluconeogenesis is affected by the anaplerotic and cataplerotic balance of oxaloacetate, which serves both as a carrier of acetyl-CoA for TCA cycle oxida- 
tion and as a gluconeogenic intermediate. Pyruvate carboxylase $(\boldsymbol{P C})$, responsible for converting pyruvate to oxaloacetate, is upregulated by increased FA concentration (White et al., 2011a). Furthermore, transcription of PC promoter 1 is specifically upregulated by FA in MDBK cells (White et al., 2012) and activation of peroxisome proliferator-activated receptor- $\alpha$ by agonist in bovines (White et al., 2011b). Examining the effect of individual FA on $P C$ suggested that C18:0 may downregulate promoter activity (White et al., 2011b); however, subsequent research with biologically relevant FA profiles indicated the importance of both FA profile and concentration in regulating $P C$ expression (White et al., 2011a, 2012). Conversely, phosphoenolpyruvate carboxykinase $(\boldsymbol{P C K})$, responsible for converting oxaloacetate to phosphoenolpyruvate as part of gluconeogenesis and thus removing oxaloacetate from the pool available for oxidation of acetyl-CoA, is upregulated as feed intake and propionate supply are increased (Greenfield et al., 2000; Hartwell et al., 2001; Zhang et al., 2016). The difference in regulatory mechanisms of $P C$ and $P C K$ and the differential response of $P C$ to changes in FA cocktail profile provide the possibility that the capacity for hepatic oxidation during the transition period may be affected by altered FA profile and concentration available to the liver.

Differential regulation by varying FA profiles suggests that subtle changes in circulating FA profile in vivo, such as during dietary FA supplement or during a fatty liver and hyperketonemic state, may have biological implications for hepatic gene expression. Thus, it is of interest to further examine how adding an individual FA to a biologically relevant profile may further regulate hepatic gene expression beyond that achieved with a basal profile. We hypothesized that exposure of primary hepatocytes to biologically relevant FA profiles with addition of individual FA, comparable with changes observed in vivo during fatty liver or dietary FA supplementation, would shift the expression of genes responsible for hepatic FA transport and gluconeogenesis. The objective of this experiment was to determine the expression of gluconeogenic and FA transport genes in primary hepatocytes exposed to a physiologically relevant FA profile that was altered to have an increased proportion of C16:0, C18:0, or C18:1.

All animal procedures were approved by the University of Wisconsin-Madison College of Agricultural and Life Sciences Animal Care and Use Committee (protocol no. A001552). Four singlet Holstein bull calves $3 \pm$ $2 \mathrm{~d}$ of age and $42.4 \pm 2.1 \mathrm{~kg}( \pm \mathrm{SD})$ were hepatocyte donors and represent biological replications. The caudate process of the liver was excised from the animal under general anesthesia and primary hepatocytes were isolated as done previously (Donkin and Armentano, 1993; Chandler and White, 2017; Zhang and White, 2017). Although cells were isolated from a neonatal bull calf, they have been previously demonstrated to be hormonally responsive and to have gluconeogenic capacity (Donkin and Armentano, 1995). Cells were plated in tissue culture-treated $35-\mathrm{mm}$ dishes (Eppendorf, Hauppauge, NY) and cultured for $24 \mathrm{~h}$. Medium was then aspirated and replaced with Dulbecco's modified Eagle's medium, low glucose (D2902-10X1L, Sigma-Aldrich, St. Louis, MO), containing 1\% FA-free BSA (820024, EMD Millipore, Burlington, MA) and $1 \%$ antibiotic, antimycotic solution (A5955-100ML, Sigma-Aldrich). Wells were randomly assigned to treatments that were applied in triplicate. Cell viability was tested using Trypan blue and counting live cells before plating (1.5-2 million cells plated/35-mm dish). Primary hepatocytes do not proliferate; therefore, plating density was used to ensure that cell confluency would be at least $80 \%$ at treatment. Cells were cultured for 24 $\mathrm{h}$ after treatments were applied and harvested into 0.5$\mathrm{mL}$ Trizol reagent (Life Technologies, Carlsbad, CA).

Treatments consisted of an FA- and hormone-free control medium containing 1\% BSA or 1 of 5 treatments containing FA bound to BSA. The FA calving cocktail as described by White et al. (2012) acted as a basal FA treatment at concentrations of 0.75 and $0.90 \mathrm{mM}$. Given that the circulating FA profile of cows at calving is unique compared with later postpartum, largely because of contributions of FA from adipose stores, it was important to use a mixture of FA that represents that of a periparturient dairy cow mobilizing FA from adipose tissue at calving. Although blood FA concentration around calving rages, it has been reported across studies as 0.60 to $1.0 \mathrm{mM}$ (McCarthy et al., 2015; Rico et al., 2015; Oliveira et al., 2019). Selection of 0.75 $\mathrm{m} M$ as the starting concentration allowed for biological relevance as well as consistency with the range of FA used in past in vitro research (White et al., 2012). To mimic achievable shifts in FA profile observed with dietary fat feeding or during hyperketonemia or fatty liver, FA content of the medium was altered by adding an additional $0.15 \mathrm{~m} M$ of $\mathrm{C} 16: 0, \mathrm{C} 18: 0$, or $\mathrm{C} 18: 1$ to $0.75 \mathrm{~m} M$ of the FA cocktail to represent variability in FA that hepatocytes may be exposed to in vivo during the transition period (Table 1). The $0.90 \mathrm{~m} M$ calving cocktail treatment served as a control for concentration after the addition of individual FA without being confounded by the increased total FA concentration.

Cells were harvested in Trizol reagent (15596026, Life Technologies) and stored at $-80^{\circ} \mathrm{C}$ until RNA isolation following the manufacturer's protocol. Total RNA of samples was quantified and quality was ensured (ratio 
Table 1. Fatty acid (FA) profiles ${ }^{1}$ and concentrations of treatments applied to primary bovine hepatocytes

\begin{tabular}{|c|c|c|c|c|c|}
\hline Item & $\begin{array}{l}0.75 \mathrm{~m} M \\
\text { cocktail }\end{array}$ & $\begin{array}{l}0.90 \mathrm{~m} M \\
\text { cocktail }\end{array}$ & $\begin{array}{c}0.75 \mathrm{~m} M \\
\text { cocktail }+ \text { C16:0 }\end{array}$ & $\begin{array}{c}0.75 \mathrm{~m} M \\
\text { cocktail }+\mathrm{C} 18: 0\end{array}$ & $\begin{array}{c}0.75 \mathrm{mM} \\
\text { cocktail + C18:1 }\end{array}$ \\
\hline \multicolumn{6}{|l|}{$\mathrm{m} M \mathrm{FA}$} \\
\hline C14:0 & 0.0225 & 0.0270 & 0.0225 & 0.0225 & 0.0225 \\
\hline C18:0 & 0.1725 & 0.2070 & 0.1725 & 0.3225 & 0.1725 \\
\hline C18:1 & 0.2325 & 0.2790 & 0.2325 & 0.2325 & 0.3825 \\
\hline C18:2 & 0.0600 & 0.0720 & 0.0600 & 0.0600 & 0.0600 \\
\hline C14:0 & 3.0 & 3.0 & 2.5 & 2.5 & 2.5 \\
\hline C16:0 & 27.0 & 27.0 & 39.2 & 22.5 & 22.5 \\
\hline C18:0 & 23.0 & 23.0 & 19.2 & 35.8 & 19.2 \\
\hline C18:1 & 31.0 & 31.0 & 25.8 & 25.8 & 42.5 \\
\hline C18:2 & 8.0 & 8.0 & 6.7 & 6.7 & 6.7 \\
\hline C18:3 & 8.0 & 8.0 & 6.7 & 6.7 & 6.7 \\
\hline
\end{tabular}

${ }^{1}$ FA cocktail formulated to mimic the profile of circulating FA in a dairy cow immediately postpartum (Rukkwamsuk et al., 2000; Douglas et al., 2007; Petit et al., 2007) and as previously described (White et al., 2012).

of absorbance at 260 and $280 \mathrm{~nm}$ between 1.9 and 2.1) using a Synergy Hybrid Spectrophotometer (BioTek, Winooski, VT). Isolated RNA from technical replicates was pooled and further purified using an on-column DNase I treatment and an RNeasy Mini Kit (74104, Qiagen, Thousand Oaks, CA) and requantified. Quality of cleaned samples was ensured (ratio of absorbance at 260 and $280 \mathrm{~nm}$ between 2.0 and 2.1) and integrity (RNA integrity number of $8.9 \pm 0.4$; mean $\pm \mathrm{SD}$ ) was verified using a Bioanalyzer 2100 (Agilent, Santa Clara, $\mathrm{CA}$ ). A volume containing $1 \mu \mathrm{g}$ of purified RNA was reverse transcribed using iScript gDNA Clear cDNA Synthesis Kit (1725034, Bio-Rad Laboratories, Hercules, $\mathrm{CA}$ ), which targets digestion of genomic DNA within a purified RNA sample before reverse transcription. Reverse transcription was completed according to the manufacturer's instructions in a C1000 Touch Thermo Cycler (Bio-Rad Laboratories).
Gene expression was determined using real-time quantitative PCR with SsoAdvanced SYBR (172-5270, Bio-Rad Laboratories) and a CFX384 Real-Time System (Bio-Rad Laboratories) as described by Zhang and White (2017) with the modifications described below. Primers used for gene expression quantification were specific for the target gene, and a single end product was verified as discussed below (Table 2). Real-time quantitative PCR was done according to the following protocol: $30 \mathrm{~s}$ at $95^{\circ} \mathrm{C}$ and 45 cycles at $95^{\circ} \mathrm{C}$ and $55^{\circ} \mathrm{C}$ for 5 and $15 \mathrm{~s}$, respectively, with a melt curve starting at $65^{\circ} \mathrm{C}$ and increasing to $95^{\circ} \mathrm{C}$ at increments of $0.5^{\circ} \mathrm{C}$ every $5 \mathrm{~s}$, which demonstrated a single end product for each gene. Efficiency of all reactions was maintained between 90 and $110 \%$ based on the standard curve of a cDNA pool (combined equal quantities from each sample and a 1:4 serial dilution used to generate 5 points to encompass the range of starting quantities present in

Table 2. Primers used for real-time quantitative PCR

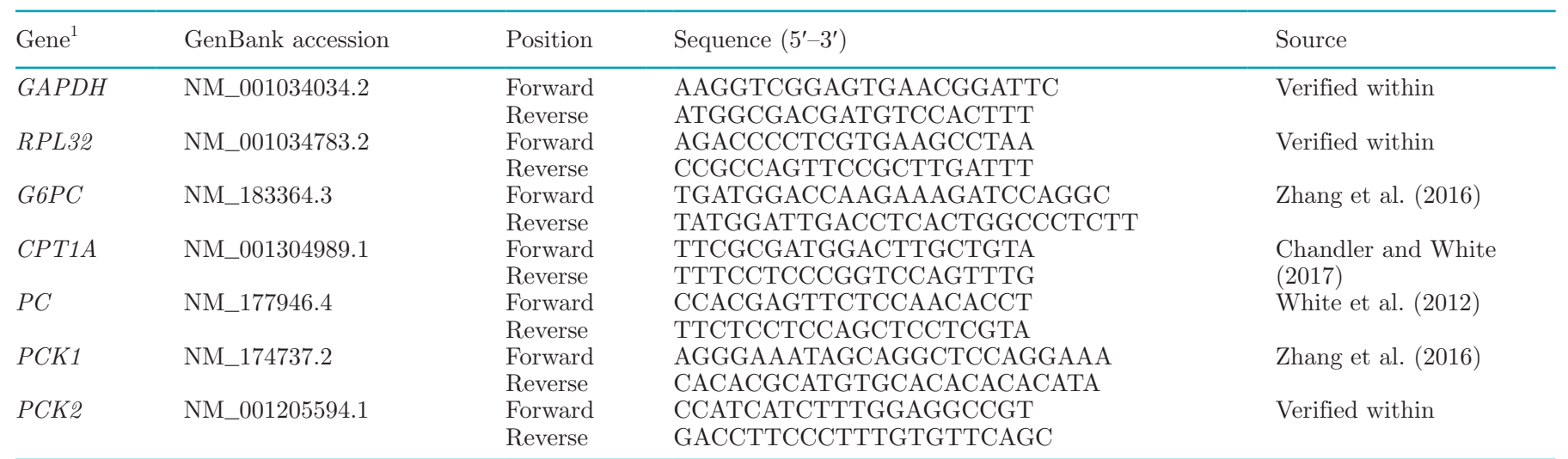

${ }^{1} R P L 32=$ ribosomal protein L32; CPT1A = carnitine palmitoyltransferase $1 \mathrm{~A} ; G 6 P C=$ glucose-6-phosphatase; $P C=$ pyruvate carboxylase; $P C K 1=$ cytosolic phosphoenolpyruvate carboxykinase; $P C K 2=$ mitochondrial phosphoenolpyruvate carboxykinase. 
the samples). Quantification cycles for unknowns were used only if within the standard curve (maximum allowed was 38) and resulted in a single end product, as verified by the dissociation curve. Quantification cycle data were then transformed to starting quantity data with Bio-Rad CFX Software (Bio-Rad Laboratories) using the standard curve of each gene.

The 2 reference genes (ribosomal protein L32 and glyceraldehyde-3-phosphate dehydrogenase) chosen were shown to be the most stable out of 3 tested using geNorm (Qbase+ Biogazelle, Zwijnaarde, Belgium; gene stability measure $\mathrm{M}=0.42$ and 0.45 , respectively, for the selected genes). Abundance of RNA for the genes of interest $[P C$, cytosolic $P C K(\boldsymbol{P C K} \mathbf{1})$, mitochondrial $P C K$ (PCK2), glucose-6-phosphatase $(\boldsymbol{G} \boldsymbol{6} \boldsymbol{P C})$, and $C P T 1 A]$, relative to the geometric mean of the reference genes, was calculated. Data were analyzed using PROC MIXED (SAS version 9.4; SAS Institute Inc., Cary, NC) to execute a model containing treatment as a fixed effect and calf in the random statement. Preplanned contrasts were the effect of FA addition (BSA vs. all FA treatments), FA concentration ( 0.75 vs. 0.90 $\mathrm{m} M$ cocktail), and the effect of specific FA enrichment (each of C16:0, C18:0, and C18:1 enrichment vs. 0.90 $\mathrm{m} M$ cocktail). Significance was defined as $P \leq 0.05$ and a tendency as $0.05<P \leq 0.10$.

Dairy cattle experience changes in circulating FA profile across the peripartum period (Rukkwamsuk et al., 2000) and further shifts in profile with dietary fat (Douglas et al., 2007; Petit et al., 2007) or with hyperketonemia or fatty liver (Rukkwamsuk et al., 2000; Weld et al., 2018). Previous work has shown that gluconeogenic genes are responsive to FA profile and that slight changes in individual FA within a biologically relevant profile may shift the expression of gluconeo- genic genes differentially (White et al., 2012). White et al. (2012) highlighted that in vitro responses to profile and concentration combinations that were physiologically relevant to specific periods during the transition to the lactation period paralleled in vivo responses. Because C16:0, C18:0, and C18:1 are the 3 primary FA mobilized from adipose tissue (Rukkwamsuk et al., 2000) and absorbed from the duodenum (Wu et al., 1991), they were chosen to add to an FA profile representative of that circulating in the transition dairy cow in concentrations relevant to a cow mobilizing FA from adipose tissue at parturition (Rukkwamsuk et al., 2000).

Compared with no FA, FA addition increased $(P=$ 0.05; Table 3) CPT1A expression 1.9-fold, which agrees with previous data in primary bovine hepatocytes (Chandler and White, 2017), rat hepatoma cells exposed to $0.2 \mathrm{~m} M$ FA (Moody et al., 2019), and MDBK cells exposed to $0.15 \mathrm{~m} M$ FA (Thering et al., 2009). In our research, a $0.15 \mathrm{mM}$ increase in FA concentration (0.75 to $0.90 \mathrm{~m} M$ FA cocktail) did not further increase $C P T 1 A$ expression $(P=0.75)$, which contrasts the increase in $C P T 1 A$ by increasing individual $\mathrm{FA}$ when the basal concentration and range were lower $(0.01 \mathrm{mM}$; Bionaz et al., 2008). Carnitine palmitoyltransferase 1A is responsible for the transport of FA across the outer mitochondrial membrane to undergo complete oxidation; thus, upregulation by FA likely allows an increase in FA transport to the mitochondria. Although CPT1A protein is also posttranslationally regulated (Brindle et al., 1985; Schreurs et al., 2010), increases in transcriptional regulation through reduced methylation and recruitment of transcription factors including CCAAT/ enhancer-binding protein- $\beta$, peroxisome proliferatoractivated receptor- $\alpha$, and peroxisome proliferator-acti-

Table 3. Effect of fatty acid (FA) profile and concentration on relative expression of gluconeogenic and oxidative genes (arbitrary units) in primary bovine hepatocytes

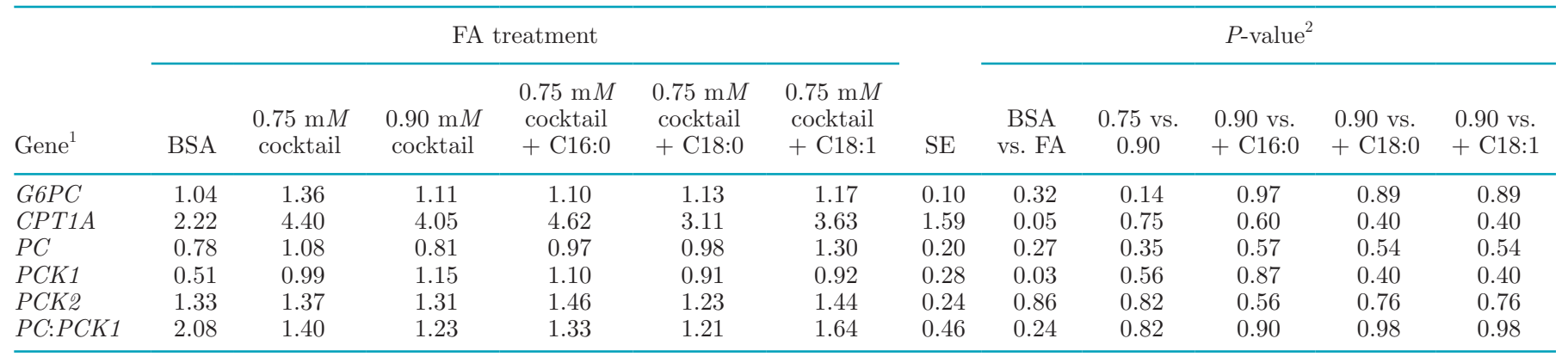

${ }^{1} G 6 P C=$ glucose-6-phosphatase; $C P T 1 A=$ carnitine palmitoyltransferase $1 \mathrm{~A} ; P C=$ pyruvate carboxylase; $P C K 1=$ cytosolic phosphoenolpyruvate carboxykinase; $P C K 2=$ mitochondrial phosphoenolpyruvate carboxykinase. Expression of genes of interest was normalized to the geometric mean of ribosomal protein L32 and GAPDH.

${ }^{2}$ Preplanned contrasts. 
vated receptor- $\gamma$ coactivator $1-\alpha$ have an important role in altering CPT1A activity (Moody et al., 2019), so transcriptional regulation still warrants examination.

Glucose-6-phosphatase is the final step of gluconeogenesis, at which point glucose is dephosphorylated and transported out of the hepatocyte. Glucose-6-phosphatase gene expression was not regulated $(P \geq 0.14)$ by FA profile or concentration in the present study, which agrees with previous research that indicated a lack of regulation by FA treatments (White et al., 2012). Expression of $G 6 P C$ was not different across the transition to the lactation period (White et al., 2016); however, enzyme activity tended to be lower prepartum in cows with induced fatty liver (Murondoti et al., 2004). Expression of $G 6 P C$ is transcriptionally regulated in nonruminants by glucose, glucocorticoids, cyclic AMP, and insulin (Lin et al., 1997; van Schaftingen and Gerin, 2002) and the enzyme posttranslationally regulated by cyclic AMP or the glucose-6-phosphate transporter, which has been demonstrated in human and rat cell models used to study endogenous glucose production (Soty et al., 2016). Glucose infusions in dairy cows did not alter expression or protein abundance previously (Al-Trad et al., 2010). Although this warrants investigation in bovines, it seems that the high activity of $G 6 P C$ in bovine hepatocytes may be evolutionarily advantageous and preclude regulation as observed in other species (Aschenbach et al., 2010).

In vivo, $P C K 1$ is generally increased as feed intake and propionate increase and circulating FA return to baseline (Greenfield et al., 2000; Karcher et al., 2007; Al-Trad et al., 2010), and mRNA expression corresponds to enzyme activity in vivo (Agca et al., 2002; Al-Trad et al., 2010). In vitro, PCK1 is regulated by changes in substrate and hormone concentrations (Zhang et al., 2016). Expression of PCK2 is considered to be more constitutively expressed and is not regulated by physiologically relevant concentrations or profiles of FA (White et al., 2012) or during the transition to the lactation period (White et al., 2016). In this experiment, $P C K 1$ was upregulated $(P=0.03)$ by the addition of FA to the medium, which differs from the linear downregulation with increasing FA concentrations of a similar FA cocktail observed previously in MDBK cells (White et al., 2012). This difference could be due to differential regulation of $P C K 1$ in kidney (MDBK) cells versus primary bovine hepatocytes. Hepatic PCK1 and $P C K 2$ were not further regulated beyond the expression achieved with the basal calving FA cocktail, with increasing the FA concentration, or addition of individual FA $(P \geq 0.40)$.

In opposition to $P C K 1$ regulation, regulation of $P C$ is responsive to feed restriction (Velez and Donkin, 2005) and at parturition (Greenfield et al., 2000; Loor et al., 2006; White et al., 2016). Expression of RNA has been shown to correspond to enzyme activity (Greenfield et al., 2000). In the present study, expression of $P C$ was not affected $(P \geq 0.35)$ by FA profile or concentration. White et al. (2012) demonstrated that $P C$ expression tended to be increased in MDBK exposed to $1 \mathrm{~m} M$ of an FA cocktail mimicking cows with induced fatty liver but not to $1 \mathrm{mM}$ of the cocktail similar to that used here. This differential response to the same concentration comprising a slightly different FA profile highlights the potential for regulation of $P C$ to be responsive to slight shifts in FA profile due to metabolic status or dietary fat feeding.

Although treatment with FA cocktails cannot determine the individual FA responsible for eliciting response, White et al. (2011b) observed that $P C$ promoter activity is downregulated by $\mathrm{C} 18: 0$ but not by $\mathrm{C} 18: 1$. The effect of C18:0 observed previously was mediated through decreases in the glucogenic tissue-specific promoter 1 with concurrent increases in promoter 2 and 3 activity (White et al., 2011b), which are expressed across tissues (Agca et al., 2004). The opposing effects of C18:0 on different promoters could neutralize each other when FA are present together, resulting in the lack of effect of C18:0 on mRNA expression, as observed in the current research. Alternatively, it is possible that the $0.15 \mathrm{~m} M$ enrichment of $\mathrm{C} 18: 0$ was not sufficient to change expression beyond what was elicited by the 0.90 $\mathrm{m} M$ cocktail, suggesting that slight shifts in C18:0 may not affect expression of hepatic $P C$ in vivo.

Given the anaplerotic and cataplerotic demand on oxaloacetate, the ratio of $P C$ to $P C K 1$ may reflect the relative availability of oxaloacetate for TCA cycle oxidation of FA (White, 2015). Serum nonesterified FA concentration and profile fluctuate, so $0.15 \mathrm{~m} M$ differences in individual FA are biologically reasonable to achieve in vivo (Rukkwamsuk et al., 2000; Douglas et al., 2007). The regulation of $P C$, but not $P C K 1$, by FA may allow for the shifting of $P C: P C K 1$ ratio, and increased $P C$ expression without a change in either $P C K$ isoform may indicate a potential increase in the oxaloacetate pool, which could allow for greater complete oxidation of FA. None of the individual FA enrichments affected $P C$ expression, nor did they alter $P C: P C K 1$ ratio $(P \geq 0.56)$, indicating that slight changes in individual FA within a biologically relevant profile may not affect hepatic oxidative capacity. Future research quantifying pathway flux in situations of shifted $P C$ : $P C K 1$ ratio is still needed.

The expression of gluconeogenic and oxidative genes has been shown to be responsive to FA profile and concentration; therefore, the purpose of this work 
was to see whether intentional shifts in the FA profile within a set concentration could alter gene regulation. These data suggest that an enrichment of $0.15 \mathrm{mM}$ of an individual FA within a total FA concentration physiologically relevant to calving $(0.90 \mathrm{~m} M)$ may be insufficient to elicit an additional change in gene expression that could affect hepatic oxidative capacity. It is possible that a greater enrichment of individual FA or greater FA concentrations could increase $P C$ expression; however, those greater shifts in FA profile may not be biologically achievable during the transition to the lactation period in vivo.

\section{ACKNOWLEDGMENTS}

Funding for this research was from USDA Hatch grant number WIS01877 from the Wisconsin Agricultural Experiment Station (Madison, WI), and graduate fellowship support was from Purina Animal Nutrition LLC (Gray Summit, MO).

\section{REFERENCES}

Agca, C., C. A. Bidwell, and S. S. Donkin. 2004. Cloning of bovine pyruvate carboxylase and 5' untranslated region variants. Anim. Biotechnol. 15:47-66.

Agca, C., R. B. Greenfield, J. R. Hartwell, and S. S. Donkin. 2002. Cloning and characterization of bovine cytosolic and mitochondrial PEPCK during transition to lactation. Physiol. Genomics 11:53-63.

Al-Trad, B., T. Wittek, G. B. Penner, K. Reisberg, G. Gabel, M. Furll, and J. R. Aschenbach. 2010. Expression and activity of key hepatic gluconeogenesis enzymes in response to increasing intravenous infusions of glucose in dairy cows. J. Anim. Sci. 88:2998-3008.

Aschenbach, J. R., N. B. Kristensen, S. S. Donkin, H. M. Hammon, and G. B. Penner. 2010. Gluconeogenesis in dairy cows: The secret of making sweet milk from sour dough. IUBMB Life 62:869-877.

Bionaz, M., C. R. Baumrucker, E. Shirk, J. P. V. Heuvel, E. Block, and G. A. Varga. 2008. Short communication: Characterization of Madin-Darby bovine kidney cell line for peroxisome proliferatoractivated receptors: Temporal response and sensitivity to fatty acids. J. Dairy Sci. 91:2808-2813.

Bionaz, M., B. J. Thering, and J. J. Loor. 2012. Fine metabolic regulation in ruminants via nutrient-gene interactions: Saturated longchain fatty acids increase expression of genes involved in lipid metabolism and immune response partly through PPAR-alpha activation. Br. J. Nutr. 107:179-191.

Brindle, N. P., V. A. Zammit, and C. I. Pogson. 1985. Regulation of carnitine palmitoyltransferase activity by malonyl-CoA in mitochondria from sheep liver, a tissue with a low capacity for fatty acid synthesis. Biochem. J. 232:177-182.

Chandler, T. L., and H. M. White. 2017. Choline and methionine differentially alter methyl carbon metabolism in bovine neonatal hepatocytes. PLoS One 12:e0171080.

Donkin, S. S., and L. E. Armentano. 1993. Preparation of extended in vitro cultures of bovine hepatocytes that are hormonally responsive. J. Anim. Sci. 71:2218-2227.

Donkin, S. S., and L. E. Armentano. 1995. Insulin and glucagon regulation of gluconeogenesis in preruminating and ruminating bovine. J. Anim. Sci. 73:546-551.

Douglas, G. N., J. Rehage, A. D. Beaulieu, A. O. Bahaa, and J. K. Drackley. 2007. Prepartum nutrition alters fatty acid composition in plasma, adipose tissue, and liver lipids of periparturient dairy cows. J. Dairy Sci. 90:2941-2959.

Greenfield, R. B., M. J. Cecava, and S. S. Donkin. 2000. Changes in mRNA expression for gluconeogenic enzymes in liver of dairy cattle during the transition to lactation. J. Dairy Sci. 83:1228-1236.

Hartwell, J. R., M. J. Cecava, and S. S. Donkin. 2001. Rumen undegradable protein, rumen-protected choline and mRNA expression for enzymes in gluconeogenesis and ureagenesis in periparturient dairy cows. J. Dairy Sci. 84:490-497.

Karcher, E. L., M. M. Pickett, G. A. Varga, and S. S. Donkin. 2007. Effect of dietary carbohydrate and monensin on expression of gluconeogenic enzymes in liver of transition dairy cows. J. Anim. Sci. 85:690-699.

Lin, B., D. W. Morris, and J. Y. Chou. 1997. The role of HNF1 alpha, HNF3 gamma, and cyclic AMP in glucose-6-phosphatase gene activation. Biochemistry 36:14096-14106.

Loor, J. J., H. M. Dann, N. A. J. Guretzky, R. E. Everts, R. Oliveira, C. A. Green, N. B. Litherland, S. L. Rodriguez-Zas, H. A. Lewin, and J. K. Drackley. 2006. Plane of nutrition prepartum alters hepatic gene expression and function in dairy cows as assessed by longitudinal transcript and metabolic profiling. Physiol. Gen. 27:29-41.

McCarthy, M. M., S. Mann, D. V. Nydam, T. R. Overton, and J. A. A. McArt. 2015. Short communication: Concentrations of nonesterified fatty acids and beta-hydroxybutyrate in dairy cows are not well correlated during the transition period. J. Dairy Sci. 98:6284-6290.

Moody, L., G. B. Xu, H. Chen, and Y. Pan. 2019. Epigenetic regulation of carnitine palmitoyltransferase 1 (Cpt1a) by high fat diet. Biochim. Biophys. Acta Gene Regul. Mech. 1862:141-152.

Murondoti, A., R. Jorritsma, A. C. Beynen, T. Wensing, and M. J. H. Geelen. 2004. Activities of the enzymes of hepatic gluconeogenesis in periparturient dairy cows with induced fatty liver. J. Dairy Res. $71: 129-134$

Oliveira, R. C., K. J. Sailer, H. T. Holdorf, C. R. Seely, R. S. Pralle, M. B. Hall, N. M. Bello, and H. M. White. 2019. Postpartum supplementation of fermented ammoniated condensed whey improved feed efficiency and plasma metabolite profile. J. Dairy Sci. 102:2283-2297.

Petit, H. V., M. F. Palin, and L. Doepel. 2007. Hepatic lipid metabolism in transition dairy cows fed flaxseed. J. Dairy Sci. 90:47804792.

Rico, J. E., V. V. R. Bandaru, J. M. Dorskind, N. J. Haughey, and J. W. McFadden. 2015. Plasma ceramides are elevated in overweight Holstein dairy cows experiencing greater lipolysis and insulin resistance during the transition from late pregnancy to early lactation. J. Dairy Sci. 98:7757-7770.

Rukkwamsuk, T., M. J. H. Geelen, T. A. M. Kruip, and T. Wensing. 2000. Interrelation of fatty acid composition in adipose tissue, serum, and liver of dairy cows during the development of fatty liver postpartum. J. Dairy Sci. 83:52-59.

Schreurs, M., F. Kuipers, and F. R. van der Leij. 2010. Regulatory enzymes of mitochondrial beta-oxidation as targets for treatment of the metabolic syndrome. Obes. Rev. 11:380-388.

Soty, M., J. Chilloux, F. Delalande, C. Zitoun, F. Bertile, G. Mithieux, and A. Gautier-Stein. 2016. Post-translational regulation of the glucose-6-phosphatase complex by cyclic adenosine monophosphate is a crucial determinant of endogenous glucose production and is controlled by the glucose-6-phosphate transporter. J. Proteome Res. 15:1342-1349.

Thering, B. J., M. Bionaz, and J. J. Loor. 2009. Long-chain fatty acid effects on peroxisome proliferator-activated receptor-alpharegulated genes in Madin-Darby bovine kidney cells: Optimization of culture conditions using palmitate. J. Dairy Sci. 92:2027-2037.

van Schaftingen, E., and I. Gerin. 2002. The glucose-6-phosphatase system. Biochem. J. 362:513-532.

Velez, J. C., and S. S. Donkin. 2005. Feed restriction induces pyruvate carboxylase but not phosphoenolpyruvate carboxykinase in dairy cows. J. Dairy Sci. 88:2938-2948. 
Weld, K. A., R. C. Oliveira, K. J. Sailer, H. T. Holdorf, S. J. Bertics, and H. M. White. 2018. Fatty acid profiles in plasma and liver lipids are influenced by hyperketonemia in dairy cows. J. Dairy Sci. 101(Suppl.):271. (Abstr.)

White, H. M. 2015. The role of TCA cycle anaplerosis in ketosis and fatty liver in periparturient dairy cows. Animals (Basel) 5:793-802.

White, H. M., E. R. Carvalho, S. L. Koser, N. S. Schmelz-Roberts, L. M. Pezzanite, A. C. Slabaugh, P. H. Doane, and S. S. Donkin. 2016. Short communication: Regulation of hepatic gluconeogenic enzymes by dietary glycerol in transition dairy cows. J. Dairy Sci. 99:812-817.

White, H. M., S. L. Koser, and S. S. Donkin. 2011a. Characterization of bovine pyruvate carboxylase promoter 1 responsiveness to serum from control and feed-restricted cows. J. Anim. Sci. 89:1763-1768.

White, H. M., S. L. Koser, and S. S. Donkin. 2011b. Differential regulation of bovine pyruvate carboxylase promoters by fatty acids and peroxisome proliferator-activated receptor-alpha agonist. J. Dairy Sci. 94:3428-3436.

White, H. M., S. L. Koser, and S. S. Donkin. 2012. Gluconeogenic enzymes are differentially regulated by fatty acid cocktails in MadinDarby bovine kidney cells. J. Dairy Sci. 95:1249-1256.

Wu, Z., O. A. Ohajuruka, and D. L. Palmquist. 1991. Ruminal synthesis, biohydrogenation, and digestibility of fatty acids by dairycows. J. Dairy Sci. 74:3025-3034.

Zhang, Q., S. L. Koser, and S. S. Donkin. 2016. Propionate induces mRNA expression of gluconeogenic genes in bovine calf hepatocytes. J. Dairy Sci. 99:3908-3915.

Zhang, Q., and H. M. White. 2017. Regulation of inflammation, antioxidant production, and methyl-carbon metabolism during methionine supplementation in lipopolysaccharide-challenged neonatal bovine hepatocytes. J. Dairy Sci. 100:8565-8577. 